\title{
Systematic review and meta-analysis of the diagnostic accuracy of ultrasonography for deep vein thrombosis
} Steve Goodacre*1, Fiona Sampson ${ }^{1}$, Steve Thomas ${ }^{2}$, Edwin van Beek ${ }^{3}$ and Alex Sutton 4

\author{
Address: ${ }^{1}$ School of Health, University of Sheffield, Regent Court, 30 Regent Street, Sheffield, S1 4DA, UK, ${ }^{2}$ Academic Vascular Unit, University of \\ Sheffield, Coleridge House, Northern General Hospital, Herries Road, Sheffield, S5 7AU, UK, ${ }^{3}$ Carver College of Medicine, University of Iowa \\ Hospitals and Clinics, Department of Radiology, 3895 JPP, 200 Hawkins Drive, Iowa City, IA 52242-1077, USA and ${ }^{4}$ Department of Health \\ Sciences, University of Leicester, 22-28 Princess Road West, Leicester, LE1 6TP, UK \\ Email: Steve Goodacre* - s.goodacre@sheffield.ac.uk; Fiona Sampson - f.c.sampson@sheffield.ac.uk; \\ Steve Thomas - s.m.thomas@sheffield.ac.uk; Edwin van Beek - edwin-vanbeek@uiowa.edu; Alex Sutton - ajs22@leicester.ac.uk \\ * Corresponding author
}

Published: 03 October 2005

BMC Medical Imaging 2005, 5:6 doi:10.1 186/147/-2342-5-6
Received: 23 May 2005

Accepted: 03 October 2005

This article is available from: http://www.biomedcentral.com/I47I-2342/5/6

(C) 2005 Goodacre et al; licensee BioMed Central Ltd.

This is an Open Access article distributed under the terms of the Creative Commons Attribution License (http://creativecommons.org/licenses/by/2.0), which permits unrestricted use, distribution, and reproduction in any medium, provided the original work is properly cited.

\begin{abstract}
Background: Ultrasound (US) has largely replaced contrast venography as the definitive diagnostic test for deep vein thrombosis (DVT). We aimed to derive a definitive estimate of the diagnostic accuracy of US for clinically suspected DVT and identify study-level factors that might predict accuracy.

Methods: We undertook a systematic review, meta-analysis and meta-regression of diagnostic cohort studies that compared US to contrast venography in patients with suspected DVT. We searched Medline, EMBASE, CINAHL, Web of Science, Cochrane Database of Systematic Reviews, Cochrane Controlled Trials Register, Database of Reviews of Effectiveness, the ACP Journal Club, and citation lists (1966 to April 2004). Random effects meta-analysis was used to derive pooled estimates of sensitivity and specificity. Random effects meta-regression was used to identify study-level covariates that predicted diagnostic performance.

Results: We identified 100 cohorts comparing US to venography in patients with suspected DVT. Overall sensitivity for proximal DVT (95\% confidence interval) was $94.2 \%$ (93.2 to 95.0 ), for distal DVT was $63.5 \%$ (59.8 to 67.0), and specificity was $93.8 \%$ (93.I to 94.4 ). Duplex US had pooled sensitivity of $96.5 \%$ (95.I to 97.6 ) for proximal DVT, $71.2 \%$ (64.6 to 77.2 ) for distal DVT and specificity of $94.0 \%$ (92.8 to 95.1 ). Triplex US had pooled sensitivity of $96.4 \%$ (94.4 to $97.1 \%$ ) for proximal DVT, $75.2 \%$ (67.7 to 81.6 ) for distal DVT and specificity of $94.3 \%$ (92.5 to 95.8 ). Compression US alone had pooled sensitivity of $93.8 \%$ (92.0 to $95.3 \%$ ) for proximal DVT, $56.8 \%$ (49.0 to 66.4 ) for distal DVT and specificity of $97.8 \%$ ( 97.0 to 98.4). Sensitivity was higher in more recently published studies and in cohorts with higher prevalence of DVT and more proximal DVT, and was lower in cohorts that reported interpretation by a radiologist. Specificity was higher in cohorts that excluded patients with previous DVT. No studies were identified that compared repeat US to venography in all patients. Repeat US appears to have a positive yield of $1.3 \%$, with $89 \%$ of these being confirmed by venography.
\end{abstract}

Conclusion: Combined colour-doppler US techniques have optimal sensitivity, while compression US has optimal specificity for DVT. However, all estimates are subject to substantial unexplained heterogeneity. The role of repeat scanning is very uncertain and based upon limited data. 


\section{Background}

Deep vein thrombosis (DVT) is an important cause of mortality and morbidity that requires accurate diagnosis. Ultrasound (US) examination has now largely replaced contrast venography as the standard test for diagnosing clinically suspected DVT [1]. Numerous studies have compared US to contrast venography in patients with clinically suspected DVT. These were most recently summarised by Kearon in 1998 who concluded that US had a sensitivity of $97 \%$ for proximal DVT, $72 \%$ for distal DVT and a specificity of $94 \%$ [2].

Meta-analytic techniques have developed rapidly in recent years. There is increasing recognition that the results of individual studies of a diagnostic test are often subject to substantial heterogeneity and that methodological factors may influence the results of studies $[3,4]$. Statistical techniques, such as meta-regression, allow researchers to explore data from systematic reviews for evidence that study-level covariates may influence diagnostic accuracy. There is also an increasing recognition that systematic reviews of diagnostic test data may be subject to publication bias, [4] although solutions to this problem, such as registries of studies, have yet to be developed.

Since US is now established as a definitive diagnostic test for DVT it is unlikely that many new studies evaluating the diagnostic accuracy of US will be forthcoming. This therefore represents an opportune time to undertake a definitive systematic review, meta-analysis and meta-regression of the diagnostic accuracy of US for clinically suspected DVT. We aimed to estimate the sensitivity and specificity of US for DVT, identify study-level covariates that are associated with variation in sensitivity and specificity, and seek evidence of publication bias in diagnostic studies of US for DVT.

\section{Methods}

We sought to identify all diagnostic cohort studies of patients with clinically suspected DVT who underwent testing with US followed by a reference standard of contrast venography. We searched Medline, EMBASE, CINAHL, Web of Science, Cochrane Database of Systematic Reviews, Cochrane Controlled Trials Register, Database of Reviews of Effectiveness, and ACP Journal Club (1966 to April 2004). The bibliographies of all articles selected for the review were scanned for potentially relevant articles that were not identified by the original search.

Two reviewers (FS and SG) screened the titles and abstracts of all articles to independently identify potentially relevant articles. Full copies of all selected articles were retrieved and reviewed by the same two reviewers, who independently selected relevant articles. At both stages of selection a Kappa score was calculated and disagreements resolved by discussion. Studies published in English, French, Spanish, Italian or German were included. Studies published in other languages were excluded. Abstracts and letters were included if they reported data in sufficient detail to allow inclusion in the analysis. If not, the authors were contacted and asked to provide details of the data or any full publications.

We specifically excluded case-control studies, in which US results in a group of patients with DVT were compared to a control group of patients without DVT; studies that used a reference standard other than venography; studies with less than ten patients; and studies of patients with suspected pulmonary embolus. Although we collected data from cohorts of asymptomatic patients and mixed cohorts (symptomatic and asymptomatic) we have only reported data here from patients with clinically suspected DVT. The role of US in asymptomatic patients has recently been systematically reviewed [5].

Two independent reviewers (ST and EvB) extracted the following data from the selected studies onto a standardised proforma: the setting for patient recruitment, any exclusion criteria, population demographics, whether recruitment was consecutive and/or data collection prospective, which US technique was used, the US operator, and the number of true positives (proximal and distal), true negatives, false positives and false negatives (proximal and distal), either as reported or calculated from the reported data. The same two reviewers also independently determined whether US was interpreted by observers blind to the venogram result, and whether venography was interpreted by observers blind to the results of US. Discrepancies were checked and resolved by an independent reviewer (FS). If it was not possible to extract the necessary data from the published report we contacted the authors for clarification. We reviewed the data reported by each study and removed studies that contained duplicated data.

\section{Statistical analysis}

Random effects models were used to estimate overall sensitivity and specificity, and a Chi-square test for heterogeneity between studies. Where 0 counts occurred for study data, a continuity correction of 0.5 was added to every value for that study in order to make the calculation of sensitivity and specificity defined. These analyses were undertaken using MetaDiSc statistical software [6] and further details of the models fitted is given elsewhere [7]. Initially all studies were analysed together and random effects meta-regression undertaken to identify potential causes of heterogeneity for sensitivity and specificity separately [8] (analysis carried out in STATA). Any covariate that showed an association with sensitivity or specificity 
( $\mathrm{p}<0.1)$ was selected, and subgroups of studies identified by such covariates were meta-analysed separately. We decided, a priori, to undertake separate analyses of different US techniques: 1) Compression US only; 2) Colour Doppler only; 3) Continuous wave Doppler only; 4) Duplex (combined compression and colour Doppler US); 5) Triplex (combined compression, colour Doppler and continuous wave Doppler US).

Funnel plots were used to explore for evidence of publication bias. For both sensitivity and specificity the standard error of the log odds of the parameter was plotted against the log odds [9].

\section{Repeat or serial US}

Repeat or serial US is often used to identify distal DVT, missed by the initial scan, that extend proximally and may thus be detected by US after an appropriate time delay (usually one week). We sought to identify studies of repeat or serial US in the main systematic review. However, we realised that we were unlikely to identify many studies that fulfilled our inclusion criteria, because of the logistic and ethical difficulties of asking patient to undergo successive US examinations followed by contrast venography. We therefore recorded separately any studies that reported use of serial or repeat US with clinical follow-up of patients, but which did not perform venography in all (or any) patients. Analysis simply consisted of recording the number of positive initial and repeat scans to estimate the yield of positive repeat scans.

\section{Results}

The flow of articles is outlined in figure 1 . We scanned 3992 titles/abstracts and selected 400 potentially relevant articles for retrieval (kappa $=0.85$ ). Review of the full articles identified 151 that met the inclusion criteria (kappa = 0.90). Review of the bibliographies of the selected articles identified six additional articles for inclusion. Six articles duplicated data published elsewhere and were excluded. We were unable to extract or analyse appropriate data from a further nine articles, despite attempts to contact the authors. Some 43 articles reported asymptomatic or mixed cohorts, so 99 articles were included in the metaanalysis. One article reported two cohorts, so the metaanalysis included a total of 100 cohorts [10-108].

\section{Characteristics of the included cohorts}

The studies reported a total of 10323 patients, with cohorts varying in size from 11 to 847 patients (median $\mathrm{N}$ $=72$ ). The studies varied in the way they reported their findings: 53 reported proximal and distal DVT separately, 19 only reported proximal DVT, three only reported distal DVT, and 25 were unclear or reported proximal and distal DVT together. DVT prevalence varied from $20 \%$ to $94 \%$ (median 48\%). The proportion of proximal DVT (of all
DVT detected) ranged from $48 \%$ to $100 \%$ (median $78 \%$ ). The mean or median age was reported by 60 studies, and ranged from 39 to 68 (median 57). The male to female ratio was reported by 65 studies, with the proportion of males ranging from $15 \%$ to $95 \%$ (median $45 \%$ ).

Cohorts were recruited from the following settings: outpatient clinic-11, inpatients-12, emergency department-4, mixed-18, and not stated-55. Recruitment was reported to be consecutive in 48 , and prospective in 67 . Twelve cohorts excluded patients with previous DVT, while 45 papers did not report any exclusion criteria. The following techniques were used: 22 used compression ultrasonography alone, five used Colour Doppler alone, 16 used continuous wave Doppler alone, 25 used triplex, 28 used duplex, and four used other techniques. Ultrasound was interpreted blind to the results of venography in 62 cohorts and was unclear in 38. Venography was interpreted blind to the ultrasound result in 56 cohorts, was interpreted by observers aware of ultrasound result in two, and was unclear in 42 .

\section{Results of meta-analysis}

Figures 2 and 3 show the Forest plots of sensitivity and specificity respectively. Point estimates of sensitivity and specificity are plotted, with $95 \%$ confidence intervals, for each cohort. Pooled sensitivity ( $95 \%$ CI, p-value for heterogeneity) for detecting any DVT was $89.7 \%$ ( 88.8 to 90.5 , $\mathrm{p}<0.001$ ). Pooled sensitivity for detecting proximal DVT was $94.2 \%$ (93.2 to 95.0, $\mathrm{p}<0.001)$ and for distal DVT was $63.5 \%$ (59.8 to $67.0, \mathrm{p}<0.001)$. Pooled specificity, calculated using data from all the studies, was $93.8 \%$ (93.1 to 94.4, $\mathrm{p}<0.001$ ). When restricted to the 53 studies reporting full data specificity was $94.2 \%$ (93.4 to 95.0, p $<0.001$ ). Great care should be taken when interpreting these estimates because of the substantial heterogeneity. It may be argued that calculating summary estimates in these circumstances is inappropriate. However, it does provide a useful baseline from which to explore heterogeneity.

\section{Results of meta-regression}

We undertook random effects meta-regression to identify possible causes for the heterogeneity. The results of metaregression are outlined in Table 1. Using a threshold of $\mathrm{p}$ $<0.1$ for statistical significance, interpretation by a radiologist, prevalence of DVT, the proportion of proximal DVT and date of publication were all significant predictors of sensitivity. The only significant predictor of specificity was exclusion of patients with a previous history of DVT.

More recently published studies, those with a higher prevalence of DVT and those with a higher proportion of proximal DVT tended to have higher sensitivity. There were 33 studies in which the operator was reported as being a 


\section{Potentially relevant studies identified and screened for retrieval, $n=3992$}

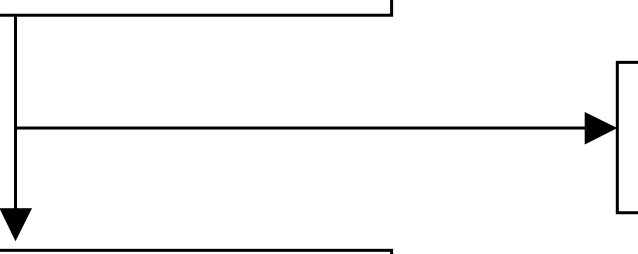

Studies excluded, $n=3592$

Studies retrieved for more detailed evaluation, $n=400$

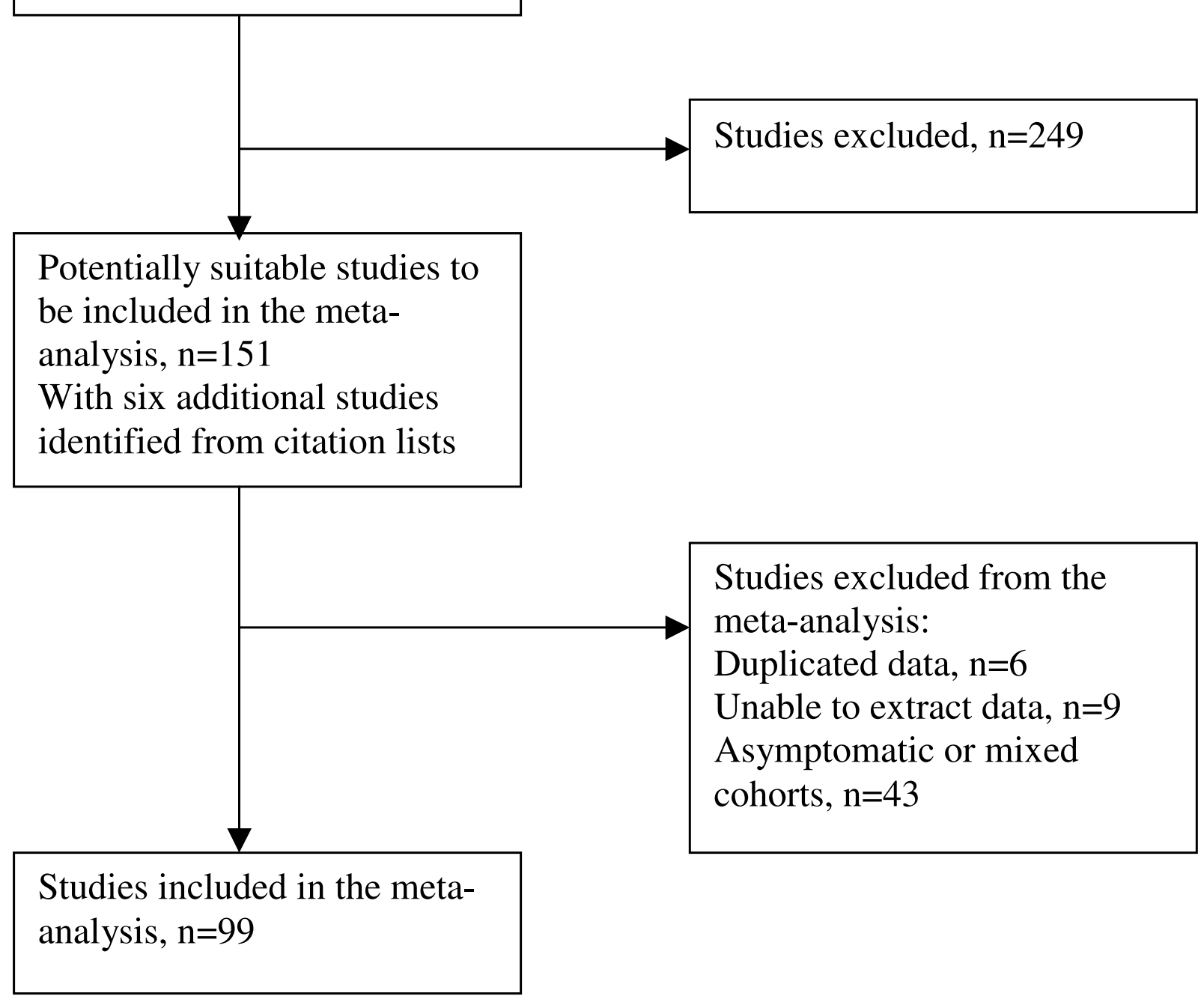

Figure I

Flow diagram of studies considered for the review. 


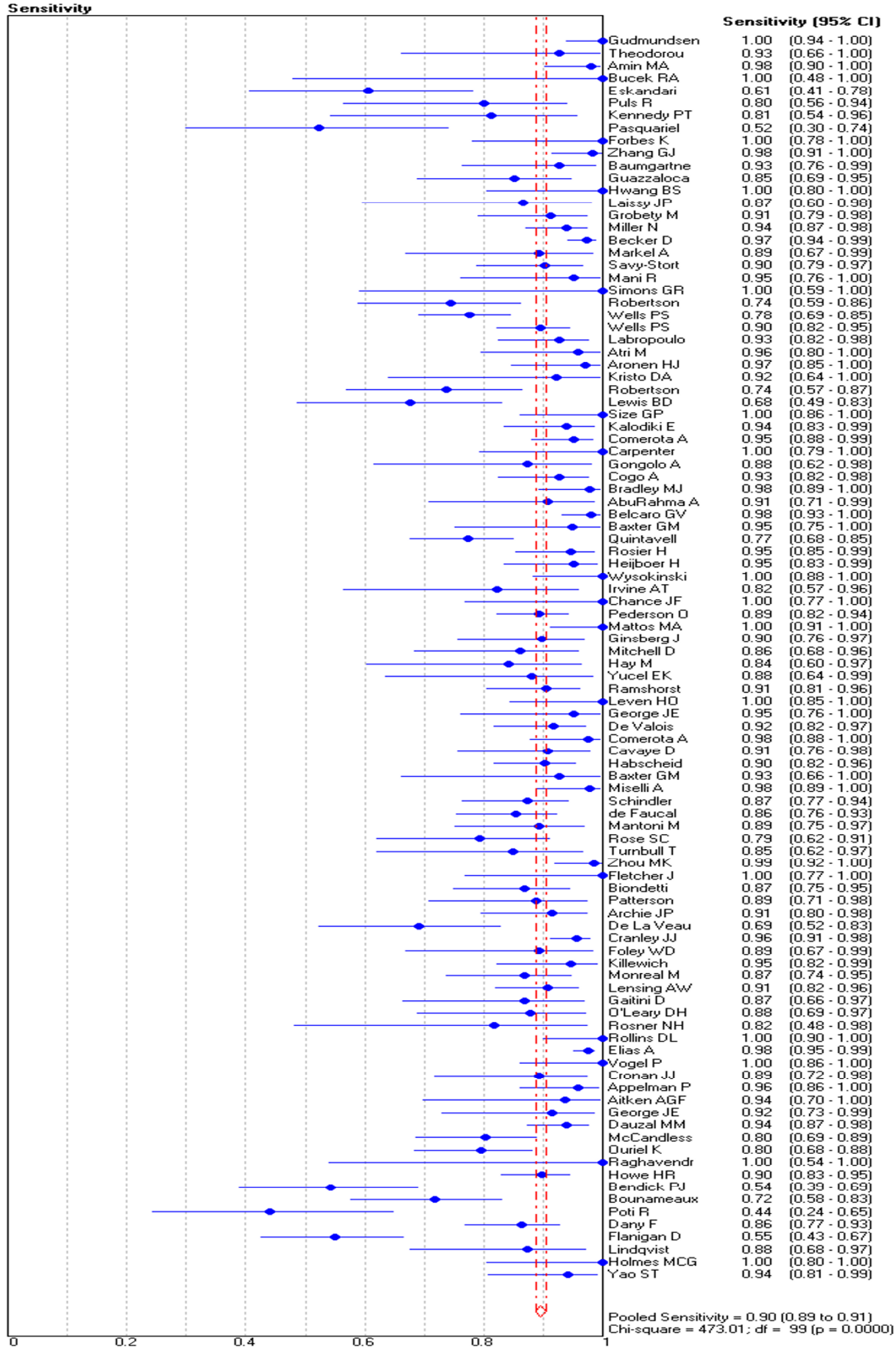

Figure 2

Forest plot of sensitivity. 


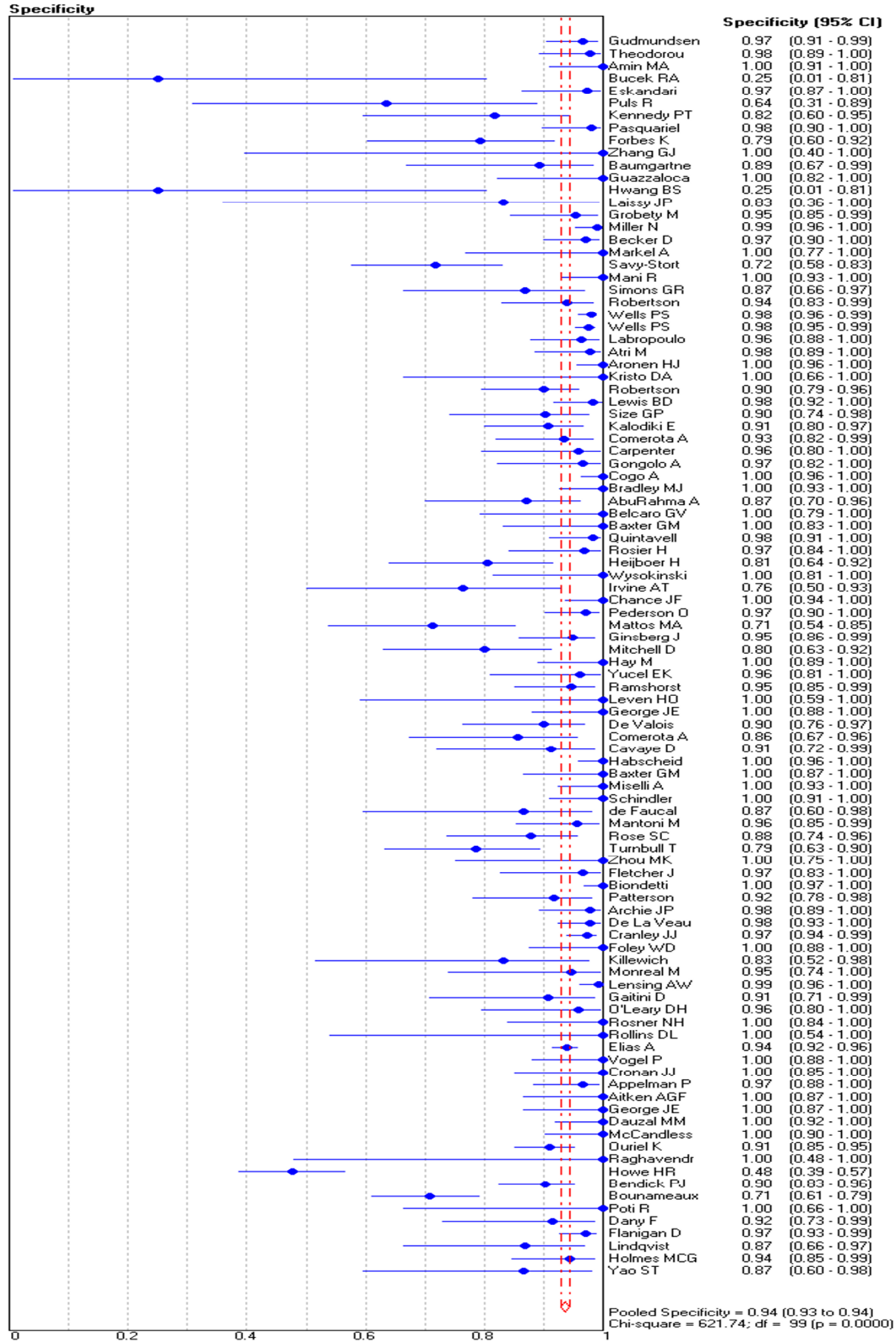

Figure 3

Forest plot of specificity. 
Table I: Results of meta-regression

\begin{tabular}{lcc}
\hline Variable & Sensitivity & Specificity \\
\hline Setting for recruitment & 0.14 & 0.43 \\
DVT prevalence & $<0.00$ I & 0.1 I \\
Proportion of proximal DVT & 0.04 & 0.14 \\
Mean age & 0.36 & 0.17 \\
Proportion of males & 0.66 & 0.24 \\
Consecutive recruitment & 0.78 & 0.55 \\
Prospective study & 0.26 & 0.24 \\
Radiologist interpreted & 0.064 & 0.52 \\
Sonographer interpreted & 0.52 & 0.44 \\
Ultrasound performed blind to reference standard & 0.44 & 0.52 \\
Reference standard performed blind to ultrasound & 0.59 & 0.56 \\
Previous DVT excluded & 0.92 & 0.039 \\
Date of publication & 0.057 & 0.84 \\
\hline
\end{tabular}

P-value when included in random effect weighted meta-regression

radiologist. Meta-analysis showed that that diagnostic performance was generally slightly worse among these studies. Overall sensitivity (95\% CI) was $86.1 \%$ (83.8 to 88.3), sensitivity for proximal DVT was $94.4 \%$ (92.3 to 96.1), sensitivity for distal DVT was 62.6\% (55.4 to 69.4), and specificity was $92.4 \%$ (90.9 to 93.7 ). Twelve cohorts reported excluding patients with previous DVT. Metaanalysis showed that that specificity was higher amongst these cohorts: $97.6 \%$ (96.6 to 98.3 ).

Table 2 shows pooled estimates of sensitivity and specificity stratified by US technique used. Optimal sensitivity is achieved by using duplex or triplex, while optimal specificity is achieved by using compression alone.

\section{Funnel plots}

These are shown in figure 4 (sensitivity) and figure 5 (specificity). Both plots are asymmetrical, suggesting that smaller studies tend to report higher sensitivity and specificity. One possible explanation of this is publication bias. Smaller studies reporting lower sensitivity or specificity may be less likely to be submitted or accepted for publication.

\section{Repeat or serial US}

We did not identify any studies that compared the results of repeat or serial scanning to venography in a complete cohort of patients, so none were included in the metaanalysis. However, we did identify several studies that reported the results of repeat US: five studies used repeat scanning for unselected cohorts with suspected DVT, [109-113] while four used repeat scanning for selected groups, based on the results of clinical risk scoring or Ddimer measurement [114-117] Three studies used venog- raphy in some patients to confirm the results of positive repeat scanning $[109,112,113]$. Results from these studies are summarised in Table 3.

In unselected cohorts repeat scanning had a positive yield of zero to $2 \%$. Where venography was used to confirm positive findings, the positive predictive value of ultrasound was 82 to $94 \%$. Overall, our best estimate of the positive yield of repeat scanning in unselected patients is $35 / 2610$ (1.34\%; 95\% CI 0.97 to $1.86 \%$ ) with a positive predictive value of $146 / 164$ (89.0\%; 95\% CI 83.3 to $92.9 \%)$.

When repeat scanning is restricted on the basis of clinical probability or D-dimer the results suggest a higher yield of positive scans, although none of the studies used venographic confirmation. Two studies of repeat ultrasound limited to patients with a positive D-dimer produced an overall positive scan yield of 22/606 (3.63\%; 95\% CI 2.42 to $5.44 \%)[116,117]$.

\section{Discussion}

The diagnostic accuracy of US for DVT varies according to the technique used. Optimal sensitivity is achieved by using duplex (proximal sensitivity 96\%, distal sensitivity $71 \%$, specificity 94\%) or triplex US (proximal sensitivity $96 \%$, distal sensitivity 75\%, specificity 94\%). Optimal specificity is achieved by using compression US alone (proximal sensitivity 94\%, distal sensitivity 57\%, specificity $98 \%$ ). These findings suggest that compression US alone is probably the appropriate technique for most patients, if scanning is aimed simply at identifying proximal DVT. Most patients have a low probability of DVT, so optimal specificity is required to avoid generating 
Table 2: Pooled estimates of sensitivity and specificity stratified by US technique

\begin{tabular}{|c|c|c|c|c|}
\hline & Sensitivity for all DVT & Sensitivity for proximal DVT & Sensitivity for distal DVT & Specificity \\
\hline $\begin{array}{l}\text { Compression } \\
\text { only, } N=22\end{array}$ & $90.3 \%(88.4$ to 92.0$) \mathrm{P}<0.00 \mathrm{I}$ & $93.8 \%(92.0$ to 95.3$) P=0.005$ & $56.8 \%(49.0$ to 66.4$) \mathrm{P}<0.001$ & $97.8 \%(97.0$ to 98.4$) P=0.01$ \\
\hline $\begin{array}{l}\text { Colour Doppler } \\
\text { only, } N=5\end{array}$ & $81.7 \%(77.4$ to 85.5$) \mathrm{P}<0.00 \mathrm{I}$ & $95.8 \%(85.7$ to 99.5$) P=0.427$ & $43.5 \%(23.2$ to 66.5$) P=0.009$ & $92.7 \%(89.7$ to 95.1$) P=0.003$ \\
\hline $\begin{array}{l}\text { Continuous } \\
\text { wave Doppler } \\
\text { only, } \\
\mathrm{N}=16\end{array}$ & $81.1 \%(78.2$ to 83.7$) P<0.001$ & $87.8 \%(84.7$ to 90.5$) P<0.001$ & $41.8 \%(32.5$ to 51.6$) P=0.015$ & $84.0 \%(81.4$ to 86.3$) \mathrm{P}<0.00 \mathrm{I}$ \\
\hline Triplex, $\mathrm{N}=25$ & $91.1 \%(89.0$ to 93.0$) \mathrm{P}<0.001$ & $96.4 \%(94.4$ to 97.9$) \mathrm{P}<0.001$ & $75.2 \%(67.7$ to 81.6$) P<0.001$ & $94.3 \%(92.5$ to 95.8$) \mathrm{P}<0.001$ \\
\hline Duplex, $N=28$ & $92.1 \%(90.7$ to 93.5$) \mathrm{P}<0.00 \mathrm{I}$ & $96.5 \%(95.1$ to 97.6$) \mathrm{P}<0.00 \mathrm{I}$ & $71.2 \%(64.6$ to 77.2$) \mathrm{P}<0.00 \mathrm{I}$ & $94.0 \%(92.8$ to 95.1$) \mathrm{P}<0.00 \mathrm{I}$ \\
\hline Others, $\mathrm{N}=4$ & $93.3 \%(88.8$ to 96.4$) P=0.338$ & - & - & $96.0 \%(92.2$ to 98.2$) \mathrm{P}<0.001$ \\
\hline
\end{tabular}

$95 \% \mathrm{Cl}$ in parentheses $\mathrm{P}$-value $=$ Chi-square test for heterogeneity

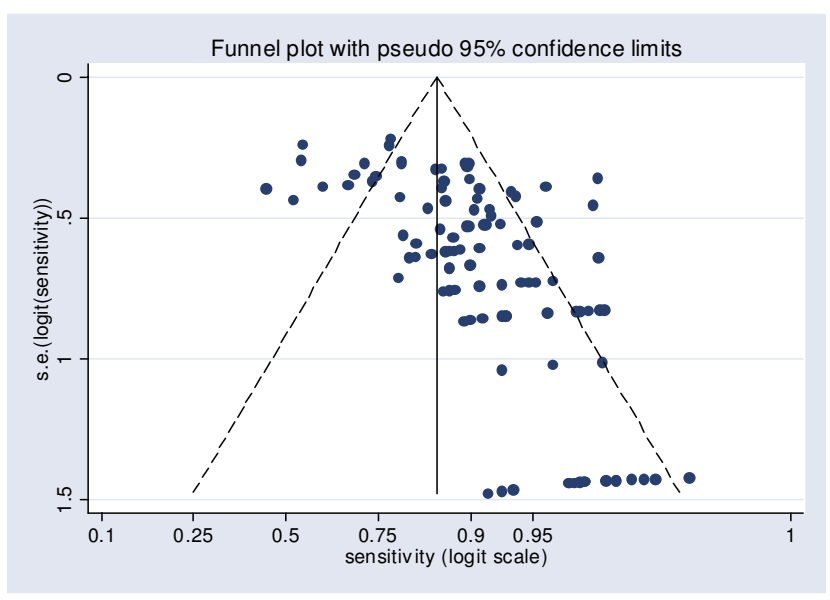

Figure 4

Funnel plot for sensitivity.

excessive false positive results. However, when evaluating patients at high risk of DVT, or if scanning aims to identify distal DVT, then duplex or triplex US will probably be the appropriate technique.

Beyond US technique we identified few study-level predictors of sensitivity or specificity. Sensitivity tended to be higher in more recent studies, probably reflecting developing technology and expertise. Sensitivity was surprisingly lower in studies where scans were interpreted by a radiologist. This may be because these studies were more likely to use techniques at an earlier stage in their development. Another cause could be that compression ultrasonography is the simplest technique, whereas Doppler and colour US techniques are more challenging and therefore more likely result in greater reporting variability. The association between proportion of proximal DVT and sen-

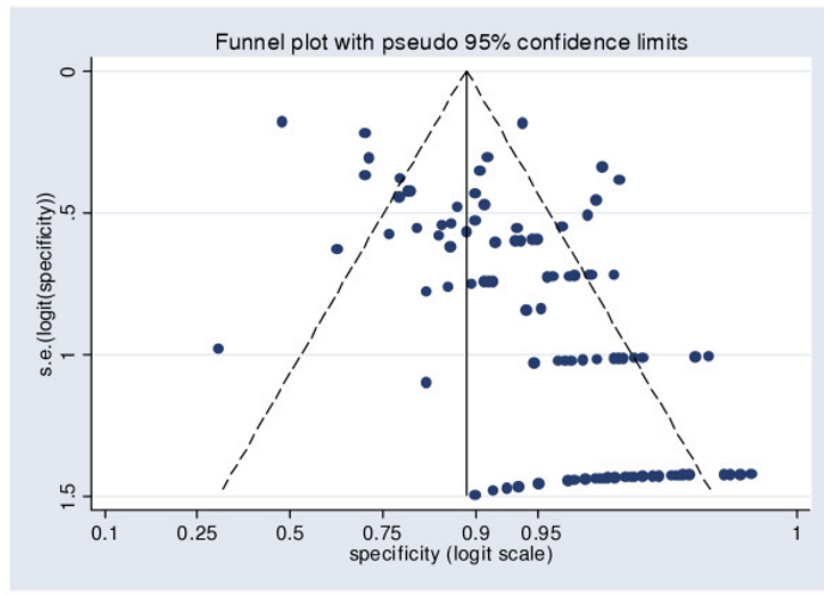

Figure 5

Funnel plot for specificity.

sitivity is unsurprising as US has better sensitivity for proximal DVT. The association between DVT prevalence in the study cohort and sensitivity may be explained by a similar mechanism. Selection of a cohort with a higher prevalence of DVT is likely to involve selection of cases with more easily detectable (i.e. larger and more proximal) DVT. Prevalence has been shown to be associated with variation in the performance of other diagnostic tests for DVT. Heim et al [118] showed that D-dimer has poorer accuracy in cohorts with a higher prevalence of DVT, probably due to lower specificity.

We identified no studies to reliably estimate the diagnostic accuracy of repeat scanning in comparison to contrast venography. Our best estimate of the diagnostic value of repeat scanning is that, in unselected patients with suspected DVT, it will have a positive yield of $1.3 \%$, of whom 
Table 3: Studies of repeat US

\begin{tabular}{|c|c|c|c|c|}
\hline $\begin{array}{l}\text { Author \& date of } \\
\text { publication }\end{array}$ & Group & $\begin{array}{l}\text { Number (\%) of initial } \\
\text { scans positive }\end{array}$ & $\begin{array}{l}\text { Number (\%) of repeat } \\
\text { scans positive }\end{array}$ & $\begin{array}{l}\text { Number (\%) of positive } \\
\text { scans (initial or repeat) } \\
\text { confirmed by } \\
\text { venography }\end{array}$ \\
\hline Heijboer, 1993 [109] & All patients & $93 / 491$ (19\%) & $7 / 397$ (1.8\%) & $84 / 89(94 \%)$ \\
\hline Cogo, 1998 [1 10] & All patients & $400 / 1702(24 \%)$ & $12 / 1252(1.0 \%)$ & - \\
\hline Sluzewski, I99I [III] & All patients & $67 / 174(39 \%)$ & $0 / 98(0 \%)$ & - \\
\hline Birdwell, 1998 [ $1 \mid 12]$ & All patients & $63 / 405(16 \%)$ & $7 / 342(2.0 \%)$ & $23 / 28(82 \%)$ \\
\hline Birdwell, 2000 [1। 3$]$ & All patients & $95 / 709$ (13\%) & $9 / 521$ (1.7\%) & $39 / 47(83 \%)$ \\
\hline $\begin{array}{l}\text { Studies of unselected } \\
\text { patients combined }\end{array}$ & & & $35 / 2610$ (1.34\%) & $146 / 164$ (89.0\%) \\
\hline Bernardi, 1998 [116] & Positive D-dimer & $260 / 946(27 \%)$ & $5 / 88(5.7 \%)$ & - \\
\hline Kraaijenhagen, 2002 [II7] & Positive D-dimer & $391 / 1739(22 \%)$ & $17 / 518(3.0 \%)$ & - \\
\hline $\begin{array}{l}\text { Studies of patients with } \\
\text { a positive D-dimer } \\
\text { combined }\end{array}$ & & & $22 / 606(3.63 \%)$ & - \\
\hline Wells, 1997 [I I4] & Intermediate Wells score & $27 / 193(14 \%)$ & $3 / 166(1.8 \%)$ & - \\
\hline Tick, 2002 [II5] & $\begin{array}{l}\text { Intermediate or high Wells } \\
\text { score \& positive D-dimer }\end{array}$ & $300 / 531$ (57\%) & $13 / 83(15.7 \%)$ & - \\
\hline
\end{tabular}

$89 \%$ will be true positive and $11 \%$ false positive. A higher yield may be achieved by limiting repeat scanning to patients with a high clinical risk score and/or positive Ddimer. Whether these yields of positive scanning justify use of repeat scanning depend upon our estimates of the costs, benefits and risks of treating, or not treating, cases of DVT.

This study has some limitations that need to be considered. We did not search for unpublished data or studies published in languages other than English, French, Spanish, Italian or German. Studies of diagnostic tests are relatively easy to undertake, are often unfunded, and are not usually recorded on research registries. It is therefore unsurprising that systematic reviews of diagnostic test data rarely search for unpublished data [4] and that the potential effect of publication bias is unknown. Funnel plots for sensitivity and specificity were both asymmetrical. One possible explanation for this is that small studies reporting poor sensitivity or specificity may be less likely to be submitted or accepted for publication. If this is the case then the values for pooled sensitivity and specificity may represent over-estimates.

Despite undertaking meta-regression and stratifying results by US technique our findings were subject to significant unexplained heterogeneity. This heterogeneity is probably due to factors that were inadequately reported in the primary studies and therefore could not be explored in meta-regression. These factors include the characteristics of patients recruited (such as the prevalence of previous thromboembolism, obesity and co-morbidities), the training and experience of US operators, specific features of the US technique (such as the US frequency used), and any time delay between scanning and venography. These factors may have had a substantial influence upon sensitivity and specificity that will not have been identified in our analysis. Poor reporting also limited our ability to explore the effect of study design upon results. Use of blinding was often not described, studies rarely reported how uncertain or equivocal test results were handled, and the median prevalence of DVT in the cohorts $(48 \%)$ suggests selective sampling of patients. These methodological weaknesses in the primary studies constitute a weakness in our meta-analysis.

The findings relating to repeat US scanning are subject to even greater limitations. Only a relatively small number of studies were identified and none compared repeat US to a venography in all cases. The potential benefit of repeat US is therefore very uncertain.

A potential clue to the influence of patient characteristics upon sensitivity and specificity is provided in a study by Wells et al [119], who reported their results stratified by the patient's clinical risk score into high, intermediate or low risk. Among patients with a high Wells score sensitivity $(95 \% \mathrm{CI})$ was $91 \%$ ( 81 to 96$)$ and specificity was 100 $\%$ (77 to 100). Among patients with an intermediate Wells score sensitivity was $61 \%$ (46 to 74 ) and specificity was $99 \%$ (94 to 100). Among patients with a low Wells score sensitivity was $67 \%$ (42 to 85 ) and specificity was $98 \%$ (95 to 99). This suggests that US sensitivity may be dependent upon clinical probability of DVT and concurs with our finding that sensitivity was higher in cohorts with higher prevalence. 
The widespread current use of US to diagnose DVT is not based upon diagnostic cohort studies alone, but also upon management studies, in which cohorts of patients with negative US results are not treated, but followed up to identify evidence of missed thromboembolism. Studies of serial US [109-112,120], a single full-leg US [121-124], or US as part of a diagnostic algorithm $[114,116,117,125-$ 129] have shown low rates of thromboembolism during three to six month follow up. This suggests that, although our meta-analysis has shown that US does not have perfect sensitivity for DVT (especially distal thrombus), this does not translate into high rates of adverse outcome. This may be because application of a reasonably sensitive test to a population with low disease prevalence will result in a high negative predictive value, or it may be because DVT that are missed by ultrasound have a relatively benign natural history.

\section{Conclusion}

US has high sensitivity for proximal DVT, modest sensitivity for distal DVT and high specificity. Optimal sensitivity, particularly for distal DVT, is achieved by using duplex or triplex US, while optimal specificity is achieved by using compression US alone. US sensitivity appears to be higher in cohorts with higher DVT prevalence. However, these findings are subject to substantial unexplained heterogeneity and should be interpreted with caution. Evaluation of repeat US has been very limited and its' potential benefit is very uncertain.

\section{List of abbreviations}

US = ultrasound

$\mathrm{DVT}=$ deep vein thrombosis

$\mathrm{CI}=$ confidence interval

\section{Competing interests}

The authors are not aware of any conflicts of interest relating to this article. The United Kingdom Health Technology Assessment R\&D Programme funded this project (reference number 02/03/01). The views and opinions expressed therein are those of the authors and do not necessarily reflect those of the UK Department of Health.

\section{Authors' contributions}

SG designed the study, selected articles for inclusion, undertook meta-analysis, and wrote the paper. FS selected articles for inclusion, assisted with data extraction, and helped write the paper. ST and EvB helped to design the study, extracted data, assessed study quality, and helped write the paper. AS assisted with meta-analysis, undertook meta-regression, created the funnel plots, and helped write the paper. All the authors have seen and approved the final draft.

\section{Acknowledgements}

We thank Angie Ryan for her help with the literature searches and Kathryn Paulucy for clerical assistance.

\section{References}

I. Sampson FC, Goodacre S, Kelly AM, Kerr D: How is deep vein thrombosis diagnosed and managed in UK and Australian emergency departments? Emerg Med J 2005 in press.

2. Kearon C, Julian JA, Newman TE, Ginsberg JS: Noninvasive diagnosis of deep venous thrombosis. McMaster Diagnostic Imaging Practice Guidelines Initiative. Ann Intern Med 1998, I 28:663-77.

3. Lijmer JG, Mol J], Heisterkamp S, Bonsel G], van der Meulen JHP, Bossuyt PMM: Empirical evidence of design-related bias in studies of diagnostic tests. JAMA 1999, 282:106I-6.

4. Song FJ, Khan KS, Dinnes J, Sutton AJ: Asymmetric funnel plots and publication bias in meta-analyses of diagnostic accuracy. Inter J Epidemiol 2002, 31:88-95.

5. Kassai B, Boissel JP, Cucherat M, Sonie S, Shah NR, Leizorovicz A: A systematic review of the accuracy of ultrasound in the diagnosis of deep venous thrombosis in asymptomatic patients. Thromb Haemost 2004, 91:655-66.

6. Zamora J, Muriel A, Abrair V: Meta-DiSc Version Beta (I.0.10): Meta-analysis of diagnostic and screening tests. 2004.

7. Deeks J]: Systematic reviews of evaluations of diagnostic and screening tests. In Systematic Reviews in Health Care: Meta-analysis in context Edited by: Egger M, Davey-Smith G, Altman DG. London: BMJ Publishing Group; 2001

8. Thompson SG, Sharp S: Explaining heterogeneity in meta-analysis: a comparison of methods. Stat Med 1999, 18:2693-708.

9. Sutton AJ, Abrams KR, Jones DR, Sheldon TA, Song F: Methods for meta-analysis in medical research. London, John Wiley; 2000.

10. Amin MA, Khan MZ, Khan MA, Tariq NA: Diagnosis of deep vein thrombosis in the leg by using colour coded duplex sonography. Journal of Ayub Medical College, Abbottabad: JAMC 200I, 13:22-3.

II. Bucek RA, Kos T, Schober E, Zontsich T, Haumer M, Potzi C, Minar $E$ : Ultrasound with Levovist in the diagnosis of suspected calf vein thrombosis. Ultrasound Med Biol 200I, 27:455-60.

12. Forbes K, Stevenson AJ: The use of power Doppler ultrasound in the diagnosis of isolated deep venous thrombosis of the calf. Clin Radiol 1998, 53:752-4.

13. Baumgartner I, Braunschweig M, Triller J, Mahler F: Power-based colour coded duplex sonography for evaluation of calf veins. Int Angiol 1998, I 7:43-8.

14. Eskandari MK, Sugimoto H, Richardson T, Webster MW, Makaroun MS: Is color-flow duplex a good diagnostic test for detection of isolated calf vein thrombosis in high-risk patients? Angiology 2000, $51: 705-10$

15. Puls R, Hosten N, Bock JS, Oellinger JH, Lemke AJ, Gutberlet M, Holz K, Felix R: Signal-enhanced color Doppler sonography of deep venous thrombosis in the lower limbs and pelvis. J Ultrasound Med 1999, 18:185-190.

16. Pasquariello F, Kurol M, Wiberg S, Krekmanova M, Leppert J: Diagnosis of deep venous thrombosis of the lower limbs: it is premature to introduce ultrasound as a routine method. Angiology 1999, 50:3 I-6.

17. Kennedy PT, Loan W, Buckley M, Rice P, Hanley P: Early experience using duplex ultrasonography in the diagnosis of deep venous thrombosis; a prospective evaluation. Ulster Med J 1999, 68:59-63.

18. Becker D, Gunter E, Strauss R, Cidlinsky K, Tomandl B, KaldenNemeth D, Neureiter D, Lang W, Hahn EG: Color Doppler imaging versus phlebography in the diagnosis of deep leg and pelvic vein thrombosis. J Ultrasound Med 1997, 16:31-7.

19. Zhang GJ, Adachi I, Duan Z, Zhang Q, Guo R, Tang L, Gong C, He S: The accuracy of color Doppler flow imaging for the detection of symptomatic deep venous thrombosis in Chinese patients. Surgery Today 1996, 26:683-687.

20. Miller N, Satin R, Tousignant L, Sheiner NM: A prospective study comparing duplex scan and venography for diagnosis of lower-extremity deep vein thrombosis. Cardiovasc Surg 1996, 4:505-8.

21. Grobety M, Depairon M, Essinger A, Bizzini G, Luthy JC, Yersin B: [Value of Doppler ultrasonic studies in the diagnosis of deep 
venous thrombosis of the lower limbs]. [French]. Jahresber Schweiz Akad Med Wiss 2003:I I 96-20I.

22. Atri M, Herba MJ, Reinhold C, Leclerc J, Ye S, Illescas FF, Bret PM, Polak JF: Accuracy of sonography in the evaluation of calf deep vein thrombosis in both postoperative surveillance and symptomatic patients. Am J Roentgenol 2003, 6: I36I-7.

23. Robertson PL, Goergen SK, Waugh JR, Fabiny RP: Colour-assisted compression ultrasound in the diagnosis of calf deep venous thrombosis. Med J Aust 1995, 163:5I5-8.

24. Labropoulos N, Leon M, Kalodiki E, al Kutoubi A, Chan P, Nicolaides AN: Colour flow duplex scanning in suspected acute deep vein thrombosis; experience with routine use. European Journal of Vascular \& Endovascular Surgery 1995, 9:49-52.

25. Simons GR, Skibo LK, Polak JF, Creager MA, Klapec-Fay JM, Goldhaber SZ: Utility of leg ultrasonography in suspected symptomatic isolated calf deep venous thrombosis. Am J Med 1995, 99:43-7.

26. Mani R, Regan F, Sheridan J, Batty V: Duplex ultrasound scanning for diagnosing lower limb deep vein thrombosis. Dermatologic Surgery 1995, 21 :324-6.

27. Savy-Stortz C, Nove-Josserand R, Dubost A, Durand DV, Levrat R: [Venous ultrasonography coupled with continuous Doppler in the diagnosis of deep venous thrombosis of the lower limbs. Evaluation in symptomatic patients]. [French]. Presse Med 1995, 24:34I-4.

28. Markel A, Weich Y, Gaitini D: Doppler ultrasound in the diagnosis of venous thrombosis. Angiology 1995, 46:65-73.

29. Aronen HJ, Svedstrom E, Yrjana J, Bondestam S: Compression sonography in the diagnosis of deep venous thrombosis of the leg. Ann Med 1994, 26:377-80.

30. Lewis BD, James EM, Welch TJ, Joyce JW, Hallett JW, Weaver AL: Diagnosis of acute deep venous thrombosis of the lower extremities: prospective evaluation of color Doppler flow imaging versus venography. Radiology 1994, 192:65।-5.

31. Robertson PL, Berlangieri SU, Goergen SK, Waugh JR, Kalff V, Stevens SN, Hicks RJ, Fabiny RP, Ugoni A, Kelly MJ: Comparison of ultrasound and blood pool scintigraphy in the diagnosis of lower limb deep venous thrombosis. Clin Radiol 1994, 49:382-90.

32. Cogo A, Lensing AW, Prandoni P, Buller HR, Girolami A, ten Cate JW: Comparison of real-time B-mode ultrasonography and Doppler ultrasound with contrast venography in the diagnosis of venous thrombosis in symptomatic outpatients. Thromb Haemost 1993, 70:404-7.

33. Bradley MJ, Spencer PA, Alexander L, Milner GR: Colour flow mapping in the diagnosis of the calf deep vein thrombosis. Clin Radiol 2003, 47:399-402.

34. Gongolo A, Giraldi E, Spreafico G, Gongolo R, Ravasini R: [Deep venous thrombosis of the legs. Diagnostic results comparing the duplex and the color-Doppler methods]. [Italian]. Radiol Med 1993, 85:182-6.

35. Rosier H, Bellin MF, Bousquet JC, Radier C, Lang T, Grellet J: [Prospective study of echography versus phlebography in the detection of sural venous thrombosis]. [French]. J de Radiol 1992, 73:579-84.

36. Belcaro GV, Laurora G, Cesarone MR, Errichi BM: Colour duplex scanning and phlebography in deep vein thrombosis. Panminerva Med 1992, 34: I-3.

37. Mattos MA, Londrey GL, Leutz DW, Hodgson KJ, Ramsey DE, Barkmeier LD, Stauffer ES, Spadone DP, Sumner DS: Color-flow duplex scanning for the surveillance and diagnosis of acute deep venous thrombosis. J Vasc Surg 1992, 15:366-375.

38. Hay M: Real-time sector compression ultrasonography $v$. contrast venography in femoropopliteal thrombosis. South African Medical Journal 199I, 80:570-2.

39. Pedersen OM, Aslaksen A, Vik-Mo H, Bassoe AM: Compression ultrasonography in hospitalized patients with suspected deep venous thrombosis. Arch Intern Med 1991, 151:2217-20.

40. van Ramshorst B, Legemate DA, Verzijlbergen JF, Hoeneveld H, Eikelboom BC, de Valois JC, Meuwissen OJ: Duplex scanning in the diagnosis of acute deep vein thrombosis of the lower extremity. Eur J Vasc Surg 199I, 5:255-260.

41. Mitchell DC, Grasty MS, Stebbings WS, Nockler IB, Lewars MD, Levison RA, Wood RF: Comparison of duplex ultrasonography and venography in the diagnosis of deep venous thrombosis. $\mathrm{Br}$ Surg |991, 78:61|-613.
42. Chance JF, Abbitt PL, Tegtmeyer CJ, Powers RD: Real-time ultrasound for the detection of deep venous thrombosis. Ann Emerg Med 199I, 20:494-6.

43. Yucel EK, Fisher JS, Egglin TK, Geller SC, Waltman AC: Isolated calf venous thrombosis: diagnosis with compression US. Radiology 1991, 179:443-6.

44. Schindler JM, Kaiser M, Gerber A, Vuilliomenet A, Popovic A, Berte $O$ : Colour coded duplex sonography in suspected deep vein thrombosis of the leg. $\mathrm{Br}$ Med J 1990, 30 I:I369-70.

45. Gudmundsen TE, Vinje B, Pedersen T: Deep vein thrombosis of lower extremities. Diagnosis by real time ultrasonography. Acta Radiol 1990, 31:473-5.

46. Miselli A, Larini P, Mandrioli R, Ugolotti U, Marcato C, Quintavalla R: Ultrasonography in the diagnosis of deep venous thrombosis of the legs. [Italian]. Radiol Med 1990, 80:469-73.

47. Biondetti PR, Vigo M, Tomasella G, Prandoni P: [Diagnosis of deep venous thrombosis of the legs: accuracy of ultrasonography using vein compression]. [Italian]. Radiologia Med 1990, 80:463-8.

48. Fletcher JP, Kershaw LZ, Barker DS, Koutts J, Varnava A: Ultrasound diagnosis of lower limb deep venous thrombosis. Med J Aust 1990, I 53:453-5.

49. Zhou MK, Pu LP, Wang ZG, Wang SH: Doppler ultrasonic diagnosis for deep venous thrombosis of lower limbs. Chin Med J (Engl) 2003, I03:27I-3.

50. Baxter GM, McKechnie S, Duffy P: Colour Doppler ultrasound in deep venous thrombosis: a comparison with venography. Clin Radiol 1990, 42:32-36.

5I. Habscheid W, Hohmann M, Wilhelm T, Epping J: Real-time ultrasound in the diagnosis of acute deep venous thrombosis of the lower extremity. Angiology 1990, 41:599-608.

52. Turnbull TL, Dymowski JJ, Zalut TE: A prospective study of handheld Doppler ultrasonography by emergency physicians in the evaluation of suspected deep-vein thrombosis. Ann Emerg Med 1990, 19:69|-5.

53. Rose SC, Zwiebel WJ, Nelson BD, Priest DL, Knighton RA, Brown JW, Lawrence PF, Stults BM, Reading JC, Miller FJ: Symptomatic lower extremity deep venous thrombosis: accuracy, limitations, and role of color duplex flow imaging in diagnosis. Radiologyy 1990, 175:639-644.

54. Cavaye D, Kelly AT, Graham JC, Appleberg M, Briggs GM: Duplex ultrasound diagnosis of lower limb deep venous thrombosis. Aust N Z J Surg 1990, 60:283-8.

55. Mantoni M: Diagnosis of deep venous thrombosis by duplex sonography. Acta Radiol 1989, 30:575-9.

56. Archie JPJ, McDaniel DN, Dean VH, Jester JE, Hall DC: Doppler ultrasound evaluation for lower extremity deep venous thrombosis in a community hospital. North Carolina Medical Journal 1989, 50:457-60.

57. Monreal M, Montserrat E, Salvador R, Bechini J, Donoso L, MaCallejas J, Foz M: Real-time ultrasound for diagnosis of symptomatic venous thrombosis and for screening of patients at risk: correlation with ascending conventional venography. Angiology 1989, 40:527-533.

58. Killewich LA, Bedford GR, Beach KW, Strandness DE Jr: Diagnosis of deep venous thrombosis. A prospective study comparing duplex scanning to contrast venography. Circulation 1989, 79:810-4.

59. Lensing AW Prandoni P, Brandjes D, Huisman PM, Vigo M, Tomasella G, Krekt J, Wouter ten Cate J, Huisman MV, Buller HR: Detection of deep-vein thrombosis by real-time B-mode ultrasonography. N Engl J Med 1989, 320:342-345.

60. Foley WD, Middleton WD, Lawson TL, Erickson S, Quiroz FA, Macrander S: Color Doppler ultrasound imaging of lower-extremity venous disease. Am J Roentgenol 2003:37I-6.

61. O'Leary DH, Kane RA, Chase BM: A prospective study of the efficacy of B-scan sonography in the detection of deep venous thrombosis in the lower extremities. J Clin Ultrasound 1988, 16:1-8.

62. Gaitini D, Kaftori JK, Pery M, Weich YL, Markel A: High-resolution real-time ultrasonography in the diagnosis of deep vein thrombosis. Rofo Fortschr Geb Rontgenstr Neuen Bildgeb Verfahr 1988 149:26-30.

63. Rollins DL, Semrow CM, Friedell ML, Calligaro KD, Buchbinder D: Progress in the diagnosis of deep venous thrombosis: the effi- 
cacy of real-time B-mode ultrasonic imaging. J Vasc Surg 1988, 7:638-4I

64. Aitken AG, Godden DJ: Real-time ultrasound diagnosis of deep vein thrombosis: a comparison with venography. Clin Radiol 1987, 38:309-13.

65. Vogel P, Laing FC, Jeffrey RB Jr, Wing VW: Deep venous thrombosis of the lower extremity: US evaluation. Radiology 1987 | 63:747-51.

66. Appelman PT, De Jong TE, Lampmann LE: Deep venous thrombosis of the leg: US findings. Radiology 1987, 163:743-6.

67. Cronan JJ, Dorfman GS, Scola FH, Schepps B, Alexander J: Deep venous thrombosis: US assessment using vein compression. Radiology 1987, 162:191-4.

68. Guazzaloca G, Palareti G, Legnani C, Fortunato G, Grauso F, Rodorigo G, De Rosa V, Golfieri R, Gianpalma E, Marri D, Pazzaglia M, Franchi R, Coccheri S: [Deep venous thrombosis. Evaluation of a non-invasive diagnostic procedure based on compression ultrasonography and measurement of D-dimer plasma levels]. [Italian]. Minerva Cardioangiol 1997, 45:259-266.

69. Laissy JP, Cinqualbre A, Loshkajian A, Henry-Feugeas MC, Crestani B, Riquelme C, Schouman-Claeys E: Assessment of deep venous thrombosis in the lower limbs and pelvis: MR venography versus duplex Doppler sonography. $A m$ J Roentgenol 2003:97I-975

70. Wells PS, Hirsh J, Anderson DR, Lensing AW, Foster G, Kearon C, Weitz J, Cogo A, Prandoni P, Minuk T, Thomson G, Benedetti L. Girolami A: Comparison of the accuracy of impedance plethysmography and compression ultrasonography in outpatients with clinically suspected deep vein thrombosis. A two centre paired-design prospective trial. Thromb Haemost 1995, 74: | 423-| 427

7I. Kristo DA, Perry ME, Kollef MH: Comparison of venography, duplex imaging, and bilateral impedance plethysmography for diagnosis of lower extremity deep vein thrombosis. South Med J 1994, 87:55-60.

72. Carpenter JP, Holland GA, Baum RA, Owen RS, Carpenter JT, Cope $C$ : Magnetic resonance venography for the detection of deep venous thrombosis: comparison with contrast venography and duplex Doppler ultrasonography. J Vasc Surg 1993, | 8:734-4l.

73. Quintavalla R, Larini P, Miselli A, Mandrioli R, Ugolotti U, Pattacini C, Pini M: Duplex ultrasound diagnosis of symptomatic proximal deep vein thrombosis of lower limbs. Eur J Radiol 1992, 15:32-36.

74. Heijboer H, Cogo A, Buller HR, Prandoni P, ten Cate JW: Detection of deep vein thrombosis with impedance plethysmography and real-time compression ultrasonography in hospitalized patients. Arch Intern Med 1992, I 52:1901-3.

75. Aburahma AF, Kennard W, Robinson PA, Boland JP, Young LL, Alberts $S$ : The judicial use of venous duplex imaging and strain gauge plethysmography (single or combined) in the diagnosis of acute and chronic deep vein thrombosis. Surgery, Gynecology \& Obstetrics 2003 1992, I 74:52-8.

76. Comerota AJ, Katz ML, Kerr R: The diagnosis of symptomatic and asymptomatic deep-vein thrombosis with venous duplex imaging. Thromb Haemost 1993, 69:1052.

77. Kalodiki E, Calahoras L, Nicolaides AN: Make it easy examination of the duplex system. Phlebology 1993, 8:17-21.

78. Theodorou SJ, Theodorou DJ, Kakitsubata Y: Sonography and venography of the lower extremities for diagnosing deep vein thrombosis in symptomatic patients. Clin Imaging 2003 27:180-3.

79. Baxter GM, Duffy P, Partridge E: Colour flow imaging of calf vein thrombosis. Clin Radiol 1992, 46:20I.

80. Bendick PJ, Glover JL, Holden RW, Dilley RS: Pitfalls of the Doppler examination for venous thrombosis. Am Surg 1983 49:6-323.

8I. Bounameaux H, Kraehenbuehl B, Vukanovic S: Diagnosis of deep vein thrombosis by combination of Doppler ultrasound flow examination and strain gauge plethysmography. An alternative to venography only in particular conditions despite improved accuracy of the Doppler method. Thromb Haemost $1982,47: 2-144$.

82. Comerota AJ, Katz ML, Greenwald LL, Leefmans E, Czeredarczuk M, White JV: Venous duplex imaging: Should it replace hemodynamic tests for deep venous thrombosis. J Vasc Surg 1990, II:I-6I.

83. Cranley JJ, Higgins RF, Berry RE, Ford CR, Comerota AJ, Griffen LH: Near parity in the final diagnosis of deep venous thrombosis by duplex scan and phlebography. Phlebology 1989, 4:74.

84. Dany F, Kim M, Brutus P, et al:: Venous Doppler ultrasonography: Methods, indications, and limits. Arch Mal Coeur Vaiss I98I, 74:862

85. De Faucal P, Planchon B, Tack P, Dupas B, Grolleau JY: Non invasive diagnosis of phlebothrombosis of the limbs. Prospective evaluation of mercury gauge plethysmography associated with ultrasonic Doppler study. J Mal Vasc 1990, 15: I-46.

86. De Laveaucoupet J, Morel MP, Philippoteau C, Simoneau G, Musset $D$ : Diagnostic value of the combination of ultrasonographyplethysmography in deep vein thromboses of the lower limbs. Ann Radiol 1989, 32:6-454.

87. De Valois JC, Van Schaik CC, Verzijlbergen F, Van Ramshorst B, Eikelboom BC, Meuwissen OJAT: Contrast venography: From gold standard to 'golden backup' in clinically suspected deep vein thrombosis. Eur J Radiol 1990, I I:2-137.

88. George JE, Berry RE: Noninvasive detection of deep venous thrombosis. A critical evaluation. Am Surg 1990, 56:2-78.

89. Ginsberg JS, Caco CC, Brill-Edwards PA, Panju AA, Bona R, Demers CM, Tuters LM, Nugent P, McGinnis J, Grant BM: Venous thrombosis in patients who have undergone major hip or knee surgery: Detection with compression US and impedance plethysmography. Radiology I991, 18 I:65 I-654.

90. Howe J, Hansen KJ, Plonk J: Expanded criteria for the diagnosis of deep venous thrombosis. Use of the pulse volume recorder and Doppler ultrasonography. Arch Surg 1984, I 19:10-1170.

91. Hwang BS, Peng YY, Jeng JS, Wu CH, Yip PK, Lin WH, Fu SH, Chang YC, Chen RC: Color Doppler ultrasonography in deep vein thrombosis of the legs: A comparison with contrast venography. J Med Ultrasound 1996, 4:85-88.

92. Irvine AT, Thomas ML: Colour-coded duplex sonography in the diagnosis of deep vein thrombosis: A comparison with phlebography. Phlebology 1991, 6:109.

93. Leven $\mathrm{HO}$, Al Hassan $\mathrm{H}$ : Ultrasonic diagnosis of iliofemora venous thrombosis: Merits and disadvantages. Phlebology 1990, 5:112.

94. McCandless ME, Young JR, Swift CL: Noninvasive diagnosis of clinically suspected deep venous thrombosis. Cleveland Clin $Q$ 1985, 52:4-560

95. Ouriel K, Whitehouse J, Zarins CK: Combined use of Doppler ultrasound and phleborheography in suspected deep venous thrombosis. Surg Gynecol Obstet 1984, 159:3-246.

96. Patterson RB, Fowl RJ, Keller JD, Schomaker W, Kempczinski RF: The limitations of impedance plethysmography in the diagnosis of acute deep venous thrombosis. I Vasc Surg 1989 9:5-730.

97. Poti R, Pini M, Megha A, Poli T: Instrumental diagnosis of deep venous thrombosis: Reliability of phleboscintigraphy and the Doppler technique with respect to phlebography. Minerva Cardioangiol 1981, 29: I I-622.

98. Raghavendra BN, Rosen RJ, Lam S, Riles T, Horii SC: Deep venous thrombosis: Detection by high-resolution real-time ultrasonography. Radiology 1984, 152:789-793.

99. Rosner NH, Doris PE: Diagnosis of femoropopliteal venous thrombosis: Comparison of duplex sonography and plethysmography. Am J Roentgenol 1988, 150:3-627.

100. Size GP, Peterson DL, Laubach M, Arcelus JI, Traverso Cl, Miller J, Caprini JA: Our experience with venous duplex imaging for the diagnosis of symptomatic deep vein thrombosis. J Vasc Technol 1993, 17:87-89.

101. Wysokinski W, Beyens G, Blockmans D, Verhaeghe R: Assessment of the patency of deep leg veins with duplex. Int Angiol I99I, 10:2-7|

102. Elias A: Discrepancies between venography and real time B mode ultrasound imaging in the diagnosis of deep vein thrombosis. Thromb Haemost 1987, 58:24. Abstract

103. Flanigan DP: Vascular-laboratory diagnosis of clinically suspected acute deep-vein thrombosis. Lancet 1978, 2:33|-4.

104. Lindqvist $R$ : Ultrasound as a complementary diagnostic method in deep vein thrombosis of the leg. Acta Medica Scandinavica 1977, 20 I:435-8. 
105. Dauzat M, Laroche J, Charras C: Real-time B-mode ultrasonography for better specificity in the noninvasive diagnosis of deep venous thrombosis. J Ultrasound Med 1986, 5:625-3I.

106. Yao ], Gourmos C, Hobbs J: Detection of proximal vein thrombosis by Doppler ultrasound flow. Lancet 1972, I:| -4.

107. George JE, Smith M, Berry RE: Duplex scanning for the detection of deep venous thrombosis of lower extremities in a community hospital. Curr Surg 1987, 44:202-4.

108. Holmes MCG: Deep venous thrombosis of the lower limbs diagnosed by ultrasound. Med J Aust 1973, I:427-30.

109. Heijboer H, Buller HR, Lensing AWA, Turpie AGG, Colly LP, Wouter ten Cate J: A comparison of real-time compression ultrasonography with impedance plethysmography for the diagnosis of deep-vein thrombosis in symptomatic outpatients. New England Journal of Medicine 1993, 329:1365-9.

1 10. Cogo A, Lensing AW, Koopman MM, Piovella F, Siragusa S, Wells PS Villalta S, Buller HR, Turpie AG, Prandoni P: Compression ultrasonography for diagnostic management of patients with clinically suspected deep vein thrombosis: prospective cohort study. BrMed J 1998, 3 | 6: 17-20.

III. Sluzewski M, Koopman MMW, Schuur KH, Van Vroonhoven TJMV, Ruijs JHJ: Influence of negative ultrasound findings on the management of in- and outpatients with suspected deepvein thrombosis. Eur J Radiol 1991, I3:174-7.

I 12. Birdwell BG, Raskob GE, Whitsett TL, Durica SS, Comp PC, George JN, Tytle TL, McKee PA: The clinical validity of normal compression ultrasonography in outpatients suspected of having deep venous thrombosis. Ann Intern Med 1998, I 28: I-7.

1 13. Birdwell BG, Raskob GE, Whitsett TL, Durica SS, Comp PC, George JN, Tytle TL, Owen WL, McKee PA: Predictive value of compression ultrasonography for deep vein thrombosis in symptomatic outpatients: clinical implications of the site of vein noncompressibility. Arch Intern Med 2000, 160:309-3I3.

1 14. Wells PS, Anderson DR, Bormanis ], Guy F, Mitchell M, Gray L, Clement C, Robinson KS, Lewandowski B: Value of assessment of pretest probability of deep-vein thrombosis in clinical management. Lancet 1997, 350:1795-1798.

I I5. Tick LW, Ton E, Van Voorthuizen T, Hovens MMC, Leeuwenburgh I, Lobatto S, Stijen PJ, Van der Heul C, Huisman PM, Kramer MH, Huisman MV: Practical diagnostic management of patients with clinically suspected deep vein thrombosis by clinical probability test, compression ultrasonography, and D-dimer test. Am J Med 2002, I | 3:630-635.

I 16. Bernardi E, Prandoni P, Lensing AW, Agnelli G, Guazzaloca G, Scannapieco G, Piovella F, Verlato F, Tomasi C, Moia M, Scarano L, Girolami $A$ : D-dimer testing as an adjunct to ultrasonography in patients with clinically suspected deep vein thrombosis: prospective cohort study. The Multicentre Italian D-dimer Ultrasound Study Investigators Group. $\mathrm{Br}$ Med J 1998, 3 I 7: 1037-1040.

I17. Kraaijenhagen RA, Piovella F, Bernardi E, Verlato F, Beckers EA, Koopman MM, Barone M, Camporese G, Potter Van Loom BJ, Prins $\mathrm{MH}$, Prandoni P, Buller HR: Simplification of the diagnostic management of suspected deep vein thrombosis. Arch Intern Med 2002, I 62:907-91।.

I I8. Heim SW, Schectman JM, Siadaty MS, Philbrick JT: D-dimer testing for deep venous thrombosis: a meta-analysis. Clin Chem 2004 , 50: I 136-47.

1 19. Wells PS, Hirsh J, Anderson DR, Lensing AWA, Foster G, Kearon C, Weitz JD'Ovidio R, Cogo A, Prandoni P: Accuracy of clinical assessment of deep-vein thrombosis. Lancet 1995 345: $1326-1330$.

120. Wolf B, Nichols DM, Duncan JL: Safety of a single duplex scan to exclude deep venous thrombosis. Br / Surg 2000, 87:| 525-8.

121. Schellong SM, Schwarz T, Halbritter K, Beyer J, Siegert G, Oettler W, Schimidt B, Schroeder HE: Complete compression ultrasonography of the leg veins as a single test for the diagnosis of deep vein thromobosis. Thromb Haemost 2003, 89:228-234.

122. Elias A, Mallard L, Elias M, Alquier C, Guidolin F, Gauthier B, Viard A mahouin $\mathrm{P}$, Vinel $\mathrm{A}$, Boccalon $\mathrm{H}$ : $\mathbf{A}$ single complete ultrasound investigation of the venous network for the diagnostic management of patients with a clinically suspected first episode of deep venous thrombosis of the lower limbs. Thromb Haemost 2003, 89:221-227.

123. Stevens SM, Elliott CG, Chan KJ, Egger MJ, Ahmed KM: Withholding anticoagulation after a negative result on duplex ultrasonography for suspected symptomatic deep venous thrombosis. Ann Intern Med 2004, I 40:985-92.

124. Shields GP, Turnipseed S, Panacek EA, Melnikoff N, Gosselin R, White $\mathrm{RH}$ : Validation of the Canadian clinical probability model for acute venous thrombosis. Acad Emerg Med 2002, 9:56I-6.

125. Wells PS, Anderson DR, Rodger M, Forgie M, Kearon C, Dreyer J, Kovacs G, Mitchell M, Lewandowski B, Kovacs MJ: Evaluation of D. dimer in the diagnosis of suspected deep-vein thrombosis. $N$ Engl J Med 2003, 349: I 227-I235.

126. Wells PS, Anderson DR, Bormanis J, Guy F, Mitchell M, Gray L, Clement C, Robinson KS, Lewandowski B: Application of a diagnostic clinical model for the management of hospitalized patients with suspected deep-vein thrombosis. Thromb Haemost 1999. 8 I:493-497

127. Anderson DR, Wells PS, Stiell I, MacLeod B, Simms M, Gray L, Robinson KS, Bormanis J, Mitchell M, Lewandowski B, Flowerdew G: Thrombosis in the emergency department: use of a clinical diagnosis model to safely avoid the need for urgent radiological investigation. Arch Intern Med 1999, I 59:477-482.

128. Walsh K, Kelaher N, Long K, Cervi P: An algorithm for the investigation and management of patients with suspected deep venous thrombosis at a district general hospital. Postgrad Med 2002, 78:742-5.

129. Bates SM, Kearon C, Crowther M, Linkins L, O'Donnell M, Douketis J, Lee AYY, Weitz JI, Johnston M, Ginsberg JS: A diagnostic strategy involving a quantitative latex D-dimer assay reliably excludes deep venous thrombosis. Ann Intern Med 2003, I 38:787-794.

\section{Pre-publication history}

The pre-publication history for this paper can be accessed here:

http://www.biomedcentral.com/1471-2342/5/6/prepub
Publish with Bio Med Central and every scientist can read your work free of charge

"BioMed Central will be the most significant development for disseminating the results of biomedical research in our lifetime. "

Sir Paul Nurse, Cancer Research UK

Your research papers will be:

- available free of charge to the entire biomedical community

- peer reviewed and published immediately upon acceptance

- cited in PubMed and archived on PubMed Central

- yours - you keep the copyright
BioMedcentral 